\title{
Governamento e pânico moral: corpo, gênero e diversidade sexual em tempos sombrios
}

\section{Government and moral panic: body, gender and sexual diversity in dark times}

\author{
Maria Rita de Assis César* \\ André de Macedo Duarte*
}

\begin{abstract}
RESUMO
Esse texto questiona as disputas contemporâneas em torno da sexualidade e do gênero nas discussões dos planos nacional, estadual e municipal de educação. Abordam-se, sobretudo, as batalhas narrativas em torno da presença dos conteúdos da igualdade de gênero e da diversidade sexual na educação brasileira, aspectos que se tornaram o centro de uma disputa pelo estabelecimento de novas formas de governamento do corpo e do desejo. Tendo em vista as noções de governo e governamentalidade de Michel Foucault, esse texto empreende uma análise genealógica daquilo que Gayle Rubin denominou de pânico moral, instaurado com o programa "escola sem homofobia" e suas repercussões no debate para a formulação dos planos de educação.
\end{abstract}

Palavras-chave: Pânico moral. Escola sem Partido. Ideologia de Gênero. Governamentalidade.

\footnotetext{
ABSTRACT

This text questions contemporary disputes concerning sexuality and gender in the discussion of the national, state and municipal Education Plans. We mainly discuss the narrative battles related to the presence of subject matters such as gender equality and sexual diversity in Brazilian education, topics which have recently been disputed in debates and polemics concerning new

DOI: $10.1590 / 0104-4060.54713$

* Universidade Federal do Paraná. Programa de Pós-Graduação em Educação. Curitiba, Paraná, Brasil. Rua General Carneiro, n 460. Centro. CEP: 80.060-150. E-mails: mritacesar@ yahoo.com.br; andremacedoduarte@yahoo.com.br
} 
forms of governing the body and the desire. Taking into consideration Michel Foucault's notions of government and governmentality, this text proposes a genealogical analysis of what Gayle Rubin has called as "moral panic", one that begun in Brazil with the Escola sem Homofobia ("School without Homophobia") program, and its repercussions on the discussions centered on the writing of educational plans.

Keywords: Moral Panic. School without Homophobia. Gender Ideology. Governmentality.

The time has come to think about sex. To some, sexuality may to be an unimportant topic, a frivolous diversion from the more critical problems of poverty, war, disease, racism, famine, or nuclear annihilation. But it is precisely at times such as these, when we live with possibility of unthinkable destruction, that people are likely to become dangerously crazy about sexuality. Contemporary conflicts over sexual values and erotic conduct have much in common with the religious disputes of earlier centuries. They acquire immense symbolic weight. Disputes over sexual behavior often become the vehicles for displacing social anxieties, and discharging their attendant emotional intensity. Consequently, sexuality should be treated with special respect in times of great social stress.

Gayle Rubin

\section{Prólogo}

No ano de 2016, a filósofa feminista Judith Butler foi à cidade de São Paulo proferir uma conferência. No local da conferência, um grupo de jovens, com trajes que faziam referência a organizações religiosas, ostentavam cartazes com os dizeres - "Judith Butler go home"; "Pela Família" e "Abaixo a ideologia de gênero", entre outros. No palco, a filósofa iniciou sua fala mencionando os "amigos" lá de fora, certamente tendo como referência as experiências norte-americanas de grupos fundamentalistas religiosos, os quais muitas vezes praticam atos de extrema violência. No Brasil, um dos países com os maiores índices de violência contra a população LGBTI - Lésbicas, Gays, Bissexuais, Travestis, Transgêneros/as e Intersex, além das altas taxas de desigualdade e violência de gênero, esses grupos religiosos fundamentalistas corroboram com 
o acirramento dessa situação, também são agentes de um conjunto de ações que, de forma crescente, vem cerceando as escolas, a produção científica de pesquisadores/as e grupos de pesquisa, assim como os movimentos sociais e ações artísticas e políticas. Já tendo conhecimento sobre a instauração do debate em torno da redação dos planos de educação, Judith Butler afirmou, em sua conferência, a necessidade da inclusão dos temas gênero e diversidade sexual nas escolas brasileiras, reiterando assim seu apoio a uma plateia que vem travando uma luta sem tréguas para que o fundamentalismo religioso, transposto para a política partidária, não destrua algumas das poucas políticas e ações que vinham garantindo a presença das discussões sobre a igualdade de gênero e a diversidade sexual nas escolas. Esta luta travada por movimentos sociais feministas e LGBTI é uma luta pela garantia dos Direitos Humanos, e dela também participam grupos de pesquisa reconhecidos pelas agências de fomento, os quais vêm produzindo conhecimento e ações político-educacionais sobre gênero e diversidade sexual há alguns anos. Com efeito, aquele pequeno grupo de religiosos fundamentalistas, assim como outros grupos organizados politicamente em partidos políticos ocupantes de cadeiras eletivas nas casas legislativas brasileiras, vêm produzindo, nos últimos anos, uma situação insustentável, pois ela corrobora para o aumento da violência contra mulheres, crianças e a população LGBTI.

\section{Das urgências do pensamento feminista}

Como o pensamento nasce das urgências e necessidades, as situações mencionadas no prólogo deste texto têm produzido modificações na agenda de pesquisa de um número importante de pesquisadores/as brasileiros, os quais procuram oferecer uma resposta àquilo que poderia ser considerado como a disputa por uma nova governamentalidade, no sentido dado por Michel Foucault (2008), sobre o corpo, o gênero, o sexo e o desejo, tal como ela pretendido por uma parte importante da classe política brasileira. (CÉSAR, 2011). No âmbito das discussões para a redação do Plano Nacional de Educação e, posteriormente, dos Planos Estaduais e Municipais, feministas, estudiosos/as das teorizações de gênero, da sexualidade e da diversidade sexual vêm se ocupando da análise desse fenômeno, tanto do ponto de vista global como local. Esse ensaio indaga sobre a produção dos documentos, ou melhor, sobre a litania em torno da formulação desses documentos, bem como sobre a tentativa de se produzir "novas" formas de governar o corpo e a sexualidade. Em sua História da Se- 
xualidade - A vontade de Saber (1984), Foucault demonstrou com seu conceito de "dispositivo da sexualidade" que a sexualidade, na modernidade, se tornara um dispositivo de controle de corpos e populações, fazendo com que o Estado penetrasse em todos os recônditos da vida para melhor controlá-la. Por certo, a noção de dispositivo da sexualidade não oferece subsídios suficientes para analisar de maneira abrangente este fenômeno no Brasil, mas ele ao menos indica a prevalência da sexualidade e do controle dos corpos no campo da política de Estado. Os movimentos conservadores do presente colocam o corpo e a sexualidade em cena de modo extremamente conservador, combatendo todas as interpretações sociológicas, antropológicas e filosóficas do corpo, do sexo e do gênero, desde o final da década de 1940, com a obra $O$ segundo sexo de Simone de Beauvoir. Para questionar esse viés, recorremos às investigações foucaultiana sobre o governo e a governamentalidade (FOUCAULT, 2008), bem como às teorizações feministas de Judith Butler (1990) e Gayle Rubin (1993). O gênero, a sexualidade e a diversidade sexual foram transformados em armas de uma guerra político-moral no contexto da chamada "ideologia de gênero", bem como dos esforços narrativos visando uma "re-naturalização" do corpo, do sexo e do desejo. Tais esforços se embasam em leituras e interpretações de textos religiosos ora precárias, ora francamente interessadas, e visam disseminar um preconceito reativo contra conquistas importantes das mulheres e da população LGBTI.

Este texto, bem como a pesquisa de que ele é parte, nasceu da urgência de investigar as produções discursivas recentes em torno da ideia de "ideologia de gênero", resgatada de textos produzidos no âmbito da igreja católica europeia continental e latino-americana, com o objetivo de combater a definição aclamada em 1995, na IV Conferência Mundial sobre a Mulher, em Pequim, a qual tinha em vista a adoção do conceito de gênero e sua prevalente construção social. No Brasil atual, tais discussões estão no centro da atividade parlamentar das bancadas fundamentalistas, na Câmara e no Senado. Num contexto de crescente conservadorismo legislativo, também se recuperou um conjunto de projetos de lei obscuros e desconhecidos até então, como o programa "Escola sem partido" (BRASIL, 2015), quase todos eles visando proibir a difusão da chamada "ideologia de gênero", o que levou a alterar a Lei de Diretrizes e Bases da Educação Brasileira - LDB, de 1996.

Com efeito, esse fenômeno de crescente conservadorismo mobilizado pelo fundamentalismo religioso não é exclusividade brasileira. Na França, quando da aprovação da lei do "casamento para todos" (Le marriage pour tous), em 2013, lei esta que modificou o código civil francês, as organizações católicas fundamentalistas realizaram manifestações com a presença de mais de um milhão de pessoas na cidade de Paris, com o slogan de defesa da infância. (PRECIADO, 2013). No contexto francês, a "ideologia de gênero" se transformou em "teoria 
do gênero" e justificou a invasão de bibliotecas escolares, a censura de projetos e materiais didáticos e o afastamento de docentes que não correspondiam às normas dos constructos de gênero e sexualidade. (BOURCIER, 2007). O presente texto não pretende comparar o fenômeno entre os dois países, mas ressalta sua ocorrência tanto no Brasil como na França, assim como em outros países, reafirmando assim a urgência de interpelar as narrativas conservadoras produzidas em resposta à conquista de direitos, em especial pela população LGTBI. Cabe recordar que no Brasil, em 2011, o Supremo Tribunal Federal reconheceu o casamento entre pessoas do mesmo sexo como a formação de entidades familiares, assim como também se propuseram ações originadas do programa do governo federal Brasil sem homofobia (BRASIL, 2004), da extinta Secretaria de Direitos Humanos - SDH.

No Brasil, testemunhamos, desde os primeiros anos da década de 2000, um conjunto de ações do Estado visando o reconhecimento dos direitos das mulheres e da população LGBTI enquanto Direitos Humanos fundamentais, cabendo mencionar, em particular, o direito à equidade de gênero e ao combate à violência contra as mulheres e à população LGBTI. Tais ações estatais decorriam de um conjunto de conquistas dos movimentos sociais feminista e LGBTI, que então passavam a fazer parte de uma agenda de governo e de governamento de corpos, sexualidade e gênero que poderia ser descrita como uma parceria entre Estado e movimentos sociais de caráter progressista. Assim, é possível afirmar que estamos agora diante de um quadro de disputa entre dois dispositivos de governamento biopolítico opostos. Tomamos a ideia de governo no sentido foucaultiano do governamento, isto é, de uma governamentalidade produzida nas políticas e narrativas de gênero, sexualidade e diversidade sexual, por agências governamentais como ministérios, secretarias de governo e, sobretudo, em parcerias (SIERRA, 2013; DAL'LGNA, 2011) com movimentos sociais e alguns poucos grupos de pesquisa. Entre avanços, debates e discussões, tais parcerias vinham definindo um campo de prioridades e ações, bem como também criaram um léxico e uma gramática "conceituais", reproduzidas em currículos, diretrizes e projetos educacionais e de educação continuada. Assim, é possível afirmar que os ataques recentes da chamada "ideologia de gênero" representam a disputa pela produção de uma nova governamentalidade de corpos, sexualidades e desejos. Com efeito, consideramos que o campo discursivo e institucional relativo ao corpo, ao gênero e à sexualidade está em disputa. Disputa política, como nos ensinou Foucault, disputa pelo estabelecimento de "novas" verdades nos campos que tratam da experiência cultural, histórica, política e subjetiva do corpo, do desejo e das experiências, ou mesmo da negação dessas experiências. Daqui em diante a pergunta a ser feita é: como serão governados os nossos corpos, os nossos prazeres e as nossas experiências? 


\section{O pânico moral como nova forma de governamento}

É possível fazer uma análise de perspectiva genealógica da última década, ou ainda uma cartografia, tendo em vista as propostas para a elaboração de políticas educacionais para a promoção da igualdade de gênero e o respeito à diversidade sexual. Desde o início da década dos anos 2000, estabeleceram-se certas políticas de enfrentamento do preconceito em relação à orientação sexual e à identidade de gênero, assim como também houve um aumento significativo no número e na força política dos movimentos sociais feminista e LGBTI. Mais precisamente, estabeleceram-se alianças e parcerias entre o governo federal e os movimentos feminista e LGBTI para o combate à violência contra as mulheres e à LGBTIfobia. (CÉSAR; DUARTE; SIERRA, 2013). Nesse processo, algumas lideranças sociais passaram a ocupar posições em ministérios e secretarias de governo, além de se tornarem consultores para as políticas públicas de educação, saúde e justiça.

Remontando ao ano de 2004, uma parceria entre o Ministério da Saúde e a Secretaria de Direitos Humanos da Presidência da República - SDH/PR elaborou o programa Brasil sem homofobia - Programa de combate à violência e à discriminação contra GLBT e promoção da cidadania homossexual. (BRASIL, 2004). Dentre as diretrizes do programa organizou-se um item exclusivo sobre o direito à educação livre de preconceito em relação à orientação sexual, isto é, o item " $V$-Direito à Educação: promovendo a paz e a não discriminação". (BRASIL, 2004, p. 05). Posteriormente, a Secretaria de Educação Continuada, Alfabetização, Diversidade e Inclusão-SECADI, do Ministério da Educação, em parceria com as Organizações Não Governamentais GALE - Global Alliance for LGBT Education, a Pathfinder do Brasil, ECOS - Comunicação e sexualidade e a $A B G L T$-Associação Brasileira de Gays, Lésbicas e Travestis, organizou o programa Escola sem homofobia, cujo principal objetivo era oferecer um conjunto de materiais de apoio para professores/as abordarem nas escolas o tema da diversidade sexual e de gênero ${ }^{1}$. O projeto visava elaborar suportes educativos para o combate à homofobia, à lesbofobia e à transfobia nas escolas ${ }^{2}$. Todavia, por conta dos procedimentos burocráticos de funcionamento das alianças e parcerias entre governo e movimentos sociais, esse material foi objeto de discussão na Assembleia Nacional, gerando polêmica de gigantesca proporção, a

1 São ressaltadas aqui as ações da Secretaria de Educação Continuada, Alfabetização, Diversidade e Inclusão (SECADI), da Secretaria Especial de Políticas para as Mulheres (SPM), do Programa Saúde e Prevenção nas escolas, do Ministério da Saúde.

2 Cf.: www.ecos.br/projetos/esh/esh.asp 
qual foi imediatamente captada pelas mídias sociais. Quando os movimentos sociais e intelectuais tentaram dialogar com os representantes legislativos a reação foi a difamação e a várias formas de violência contra seus/suas defensores/as, isto é, ativistas, intelectuais e educadores/as. No curso deste embate, o referido material foi rechaçado não somente por parlamentares pertencentes à bancada ultraconservadora fundamentalista religiosa, mas também por deputados de frentes progressistas, em razão da crise política que ali se instaurava. Vários deputados e senadores conservadores diziam que as peças produzidas no contexto do programa "escola sem homofobia" seriam "propaganda" LGBT (CÉSAR; CUNHA, 2016). Em termos pejorativos, o programa foi designado pelos parlamentares e por parte da grande mídia como o "kit gay", iniciando-se assim o processo recente de pânico moral no Brasil (RUBIN, 1993), o qual se acirrou posteriormente com os debates sobre a redação dos Planos de Educação. Nessa breve genealogia, a recusa em 2011 do chamado "kit gay" é o marco zero do nosso recente pânico moral.

Três anos antes, em 2008, fora realizada a $1^{\text {a }}$. Conferência Nacional GLBT, em meio a uma iniciativa da Secretaria Especial dos Direitos Humanos - SDH. No âmbito daquela Conferência, deu-se especial atenção ao tema da educação em virtude da violência promovida pela instituição escolar à população LGBT. O eixo temático que tratou do tema da educação elaborou uma extensa lista de deliberações e, dentre estas, uma que explicitava a dificuldade de acesso e permanência da população LGBT nas instituições escolares, problema já analisado em pesquisas. (SANTOS, 2010). Assim, a proposição de número 4 (quatro) deliberou sobre a necessidade de:

Propor e adotar medidas legislativas, administrativas e organizacionais necessárias para garantir a estudantes o acesso e a permanência em todos os níveis e modalidades de ensino, sem qualquer discriminação por motivo de orientação sexual e identidade de gênero. (BRASIL, 2008, p. 209).

Ainda no âmbito das referidas Conferências, entre 28 de março e $1^{\circ}$ de abril de 2010, foi realizada a $1^{a}$ Conferência Nacional da Educação Básica CONAE 2010, precedida por vinte e seis Conferências estaduais e uma distrital, as quais contaram com representantes de grande parte dos movimentos feminista e LGBT. (BRASIL, 2010, 2014). De acordo com o documento referência da CONAE 2010, a mobilização nacional em torno da educação visava contribuir "para a proposição de políticas direcionadas: à garantia de inclusão social, ao respeito à diversidade; [...] em consonância ao disposto na Constituição Federal 
de 1988." (BRASIL, 2010, p. 03). Tendo em vista o próprio texto da CONAE, explicitava-se a relação entre governo, movimento social organizado e educação, visando à inclusão das temáticas relativas ao respeito à diversidade. Esse processo de diálogo e de negociações entre os movimentos sociais e o Estado só foi possível por meio do primado conferido à identidade social, sexual e jurídica, fixando os sujeitos e suas experiências em identidades rígidas, estáveis e incomunicáveis, aspecto que contribuía para compartimentalizar os próprios movimentos sociais. (CÉSAR; SANTOS, 2015). No interior da lógica daquelas parcerias, temia-se pelo risco de um processo de governamentalização dos movimentos sociais. Segundo essa perspectiva analítica, os movimentos sociais corriam o risco de perder sua capacidade de reflexão e autorreflexão críticos, à medida que iam sendo e se deixando ser capturados pelo Estado. (CÉSAR; DUARTE; SIERRA, 2013).

As lutas sociais traduzidas nas Conferências e a crescente reação dos segmentos políticos e sociais ultraconservadores e fundamentalistas religiosos culminaram nos embates em torno da redação e aprovação do Plano Nacional de Educação - PNE, que na sua minuta incluíra no texto, ainda que timidamente, uma menção à igualdade de gênero e raça-etnia, assim como o respeito à diversidade sexual. (BRASIL, 2014). Os setores conservadores da sociedade brasileira e uma parte ultraconservadora do Parlamento se mobilizaram, junto com grupos religiosos católicos e neopentecostais, manifestando-se contrariamente à inserção do diminuto parágrafo sobre o respeito e a promoção da igualdade de gênero e da diversidade sexual e étnico-racial, que representara grande conquista nas Conferências. Por votação no Congresso Nacional o parágrafo foi retirado. No curso desse processo, os movimentos sociais e os grupos e sociedades de pesquisa se mobilizaram a favor da manutenção do texto, mas foram derrotados. Essas derrotas se deram, portanto, no contexto de acirramento do pânico moral já iniciado em 2011 com o rechaço ao programa Escola sem Homofobia, apelidado pejorativamente de "kit gay". Se pensarmos nos termos de una genealogia do nosso recente pânico moral, ele se iniciou com as polêmicas em torno ao "kit gay" e prosseguiu com a introdução no debate nacional da noção de "ideologia de gênero", dando prosseguimento ao pânico moral. O emprego da noção de "ideologia de gênero" visa desmerecer e criminalizar a produção acadêmica e dos movimentos sociais em torno das questões relativas à igualdade de gênero e do respeito à diversidade sexual. Os cartazes contra Butler e, consequentemente, contra a "ideologia de gênero", que mencionamos no prólogo deste texto, exprimem um claro repúdio à produção acadêmica e intelectual que critica as concepções do corpo e da sexualidade como lugares naturalizados e que recusa denominar como patológicas as experiências de gênero e sexuais não-heteronormativas. (BUTLER, 1990). Nesse sentido, 
pode-se observar que há perfeita compreensão das reflexões de Judith Butler e das teorizações feministas nos textos que informam a "ideologia de gênero" no âmbito do catolicismo.

A primeira referência à ideia de ideologia vinculada ao conceito de gênero aparece em 1998, na conferência episcopal do Peru, em uma nota intitulada $L a$ ideologia de género: sus peligros y alcances. O documento é dividido em onze tópicos e, ao longo de suas dezesseis páginas, discorre sobre a existência de uma natureza humana originada em uma lei natural completamente imutável, criada por Deus e comprovada cientificamente pela biologia. Ali se procura demonstrar como os "defensores de uma ideologia de gênero" promovem a destruição da família, da educação, da cultura e, principalmente, da religião. (CONFERÊNCIA EPISCOPAL PERUANA, 1998) A nota faz referência à $I V t h$. World Conference on Women - UN, realizada em Beijing em 1995, considerando-a como o lançamento de uma campanha de difusão de uma nova perspectiva de gênero. De fato, na definição da UN sobre o conceito de gênero, tratava-se de "passar de uma análise da situação da mulher baseada no aspecto biológico, para uma compreensão das relações entre homens e mulheres como produto de padrões determinados social e culturalmente, e, portanto, passíveis de modificação." (ONU, 1995). Em contraponto à definição construída na conferência de Beijing, a nota peruana reforçava a existência natural de um homem e uma mulher naturais, bem como considerava o sexo como sendo uma característica exclusivamente biológica.

A nota da conferência episcopal fazia uso dos conceitos de hegemonia, desconstrução, patriarcado, heterossexualidade compulsória, orientação sexual e homofobia, chegando a citar Gender Trouble (1990), de Judith Butler, e Compulsory heterosexuality and lesbian existence (1993), de Adrienne Rich. Apoiado nos trabalhos da jornalista católica Dale O'Leary ${ }^{3}$, a nota fazia uma diferenciação entre o que a autora chamara de "feminismo da igualdade" e um "feminismo de gênero/feminismo radical", sendo que o primeiro estaria ligado

3 Daele O'Leary é escritora e jornalista norte-americana amplamente citada por fundamentalistas brasileiros. Dentre suas publicações destacam-se dois livros: "One Man, One Woman: A Catholic's Guide to Defending Marriage" e "The Gender-Agenda: Redefining Equality", no qual a autora lista os princípios que guiam os "ideólogos de gênero": a abolição das diferenças entre homens e mulheres e a abolição da maternidade em tempo integral, acesso livre a contraceptivos, o aborto e a promoção do comportamento homossexual, educação sexual para crianças e jovens e abolição dos direitos dos pais sobre seus filhos, a obrigação de emprego lucrativo para todas as mulheres, o desprezo da religião. Ela afirma que os "ideólogos de gênero" estão firmemente presentes nas universidades e no governo e que uma batalha pelo senso comum poderia ter sido facilitada se o perigo dessa ideologia tivesse sido descoberto mais cedo. Para saber mais acessar: $<$ https://goo. gl/J3akUt>. Acesso em: 15 Abr. 2017. 
a uma crença de igualdade legal e moral entre sexos e o segundo pregaria a ideia de que a mulher está presa a um sistema patriarcal de opressão:

[...] as "feministas do gênero" consideram que quando a mulher cuida de seus filhos no lar e o marido trabalha fora de casa, as responsabilidades são diferentes e, portanto, não igualitárias. Então vêm esta "desigualdade" no lar como causa de "desigualdade" na vida pública, já que a mulhercujo interesse primário é o lar - nem sempre tem tempo e energia para se dedicar à vida pública. [...] Ademais, as "feministas do gênero" insistem na desconstrução da família não só porque - segundo elas - escraviza a mulher, mas também porque condiciona socialmente os filhos para que aceitem a família, o matrimônio e a maternidade como algo natural. (CONFERÊNCIA EPISCOPAL PERUANA, 1998)

A nota relacionava o "feminismo de gênero/radical" ao Marxismo como base ideológica, embora o foco se deslocasse dos problemas econômicos para atacar a família e a natureza com o objetivo de destruir a sociedade e a educação, visando também "impulsionar a agenda homossexual-lésbica-bissexual-transexual”. (CONFERÊNCIA EPISCOPAL PERUANA, 1998).

Em meio a essa disputa foram definidos os alvos a ser protegidos, isto é, a família e a criança, o que corrobora exatamente a formulação de Gayle Rubin em sua história dos pânicos morais nos Estados Unidos do final do século XIX até meados do XX. Se nos EUA e na França a máxima proteção se concentra na criança, no Brasil a família nuclear é o centro da preocupação. Rubin também relaciona as eclosões ultraconservadoras a crises políticas e econômicas concomitantes, como, por exemplo, a guerra fria nos Estados Unidos, assim como também aos períodos de grandes mudanças sociais e de costumes, sobretudo oriundos dos movimentos civis e do feminismo. Rubin centra sua reflexão na violência contra segmentos da população que são tornados alvos do pânico moral. Para a autora:

Durante o pânico moral, alguns medos atacam desafortunadas atividades sexuais e populações. A mídia se torna inflamada de indignação, o público se comporta como uma plebe raivosa, a polícia é chamada e o Estado põe em ação novas leis e regulamentos. Quando o furor passou, algum grupo erótico inocente foi dizimado e o Estado estendeu seu poder para novas áreas do comportamento erótico. (RUBIN, 1993, p. 25). 
Em se tratando de uma genealogia, concentramos a atenção não apenas nas narrativas ultraconservadoras, isto é, aquelas que promovem os pânicos morais, mas também nas narrativas produzidas em defesa da inserção da igualdade de gênero e diversidade sexual. Estas últimas compõem um conjunto heterogêneo e importante de narrativas que, concorrendo entre si, também tentam definir e estabelecer os discursos verdadeiros sobre gênero, sexualidade e diversidade sexual na educação brasileira. Se no passado o discurso médico e psicológico se estabeleceu como o discurso de verdade sobre o sexo e a sexualidade (CÉSAR, 2009), nos últimos anos as narrativas que defendem a inserção dessas temáticas encontram-se em um campo de disputa interna. Reproduzem-se atualmente num imenso campo de pesquisa de múltiplas correntes teórico-epistemológicas, diferentes definições de corpo, de gênero e de sexualidade. Nessa disputa interna ao campo progressista também participam os movimentos sociais e os sujeitos sociais que, através das mídias sociais, também participam do debate. Atualmente observa-se um grande embate sobre o direito da fala, isto é, sobre quem pode falar, quem tem direito à palavra ou quem não tem esse direito, porque supostamente gozaria de privilégios de classe, gênero, orientação sexual, raça etc. Enfim, no campo progressista, observa-se o desenrolar de uma luta de classe, raça, identidade de gênero, orientação sexual, escolaridade, geração, entre outras categorias sociais que se multiplicam rapidamente. Grupos e personalidades das mídias sociais se comportam como se inventassem, pela primeira vez e a partir do zero, o feminismo e demais lutas contra os preconceitos de classe, identidade de gênero e orientação sexual. Instaura-se assim um campo de guerra dentro de um mesmo território progressista, uma guerra no interior da grande guerra narrativa. Assim, em meio a uma profusão de narrativas produzidas sempre para deslegitimar a fala do outro, do ponto de vista estratégico todas/os perdem com essa batalha no interior do campo progressista. Por outro lado, a narrativa neoconservadora assume clara vantagem por se apresentar como um campo ultracoeso. Do ponto de vista genealógico e biopolítico, as lutas narrativas seguem e em algum momento alguém ou uma narrativa sairá vitoriosa, se tornará verdade hegemônica.

Os atores sociais são múltiplos, de um lado, há os/as parlamentares ultraconservadores/as, os grupos religiosos e os respectivos segmentos da grande mídia falada e escrita. Do outro lado, se é que o campo progressista pode ser considerado como um lado único, há os movimentos sociais, os grupos de pesquisa, as sociedades científicas, as redes sociais e as mídias alternativas. De um lado, a instalação do pânico moral traduzida pela "ideologia de gênero", isto é, a afirmação do modelo heteronormativo, machista, misógino e LGBTfóbico, promovendo uma narrativa que visa preservar um ideal fantasmático de família contra a sua suposta destruição. Do outro lado, um conjunto heterogêneo de 
narrativas progressistas, liberais, humanistas, libertárias, pós-humanistas, feministas, queer, informadas pelos saberes das ciências sociais e humanas, além de um conjunto de conhecimentos produzidos no âmbito dos movimentos sociais, das mídias sociais e das práticas sociais. Nesse campo há, inclusive, alguns segmentos pouco numerosos, mas muito barulhentos, os quais têm atacado veementemente o saber acadêmico produzido há muitas décadas entre a rua e as universidades. Enfim, personagens de uma batalha.

Para concluir essas considerações, pensamos que certas reflexões de Foucault e de Butler podem nos ajudar a redefinir os impasses que têm marcado as ações dos agentes do campo progressista. Por certo, não há como escapar à polaridade entre os grupos conservadores e os grupos progressistas em seu embate por estabelecer posições hegemônicas de poder e saber, as quais virão a se traduzir em verdades transpostas num aparato legal e governamental. No entanto, parece-nos urgente superar as batalhas fratricidas que têm cindido e enfraquecido o campo progressista. Para tanto, as ponderações de Foucault sobre a "atitude crítica" podem constituir importante fonte de inspiração. Em uma interessante conferência de 1978, "Qu'est-ce que la critique", Foucault afirmou que a tarefa da crítica não é aquela que se fecha sobre si mesma e, assim, se coloca para si uma única e absoluta verdade, a ser seguida numa recusa incondicional contra toda e qualquer forma de governo, contra toda e qualquer forma de exercício de poder e de saber. Ao contrário, Foucault ressaltou que o trabalho da crítica é sempre pontual e nunca totalizador, de modo que resistir contra as pretensões do poder e do saber hegemônicos é contrapor-lhes a seguinte ressalva: "como não ser governado deste modo, por aqueles lá, em nome desses princípios, em vista de tais objetivos e por meio destes procedimentos, não desse modo, não por isto, não por eles." (FOUCAULT, 2016, p. 37). Se todo processo de governamentalização é também um processo em que práticas e relações de poder-saber visam assujeitar os indivíduos e as populações ao vinculá-los à definição de uma verdade sobre eles, então a atitude crítica, também definida por Foucault como a atitude da "inservidão voluntária" e da "indocilidade refletida", será justamente aquele "movimento pelo qual o sujeito se dá o direito de interrogar a verdade sobre seus efeitos de poder e o poder sobre seus discursos de verdade." (FOUCAULT, 2016, p. 39). Em suma, o campo progressista precisa compreender que a atitude crítica não é aquela que estabelece uma verdade única e contrária à verdade estabelecida pelos adversários, mas sim a atitude desconfiada e pontual que define estratégias e formas de luta em comum contra o modo como os poderes e saberes vigentes pretendem nos governar e nos assujeitar.

Finalmente, parece-nos também que essa atitude crítica proposta por Foucault se complementa perfeitamente com certas reflexões propostas por Butler, em particular no que se refere à sua proposta de uma concepção "anti- 
-fundacionalista para a política de coalizão" (BUTLER, 1990, p. 15). Para Butler, tal política de coalizão não pretenderia estabelecer um consenso primeiro ou definitivo em torno do significado ou da verdade de cada sujeito (homem, mulher, gay, lésbica, trans, intersex, negro/a, indígena etc.), tampouco teria como meta alcançar tal consenso ou unidade, mas se organizaria no curso de lutas comuns, capazes de associar e identificar agentes políticos distintos, preservando, contudo, suas diferenças e distinções:

Talvez uma coalizão precise reconhecer suas contradições e agir com tais contradições intactas. Talvez parte daquilo que a compreensão dialógica propicia seja a aceitação da divergência, da quebra, da divisão e da fragmentação como parte do processo tortuoso de democratização. (BUTLER, 1990, p. 14-15).

Atitude crítica e políticas de coalizão, eis algumas sugestões de Foucault e de Butler que nos parecem incontornáveis se quisermos nos engajar num processo de luta e resistência que não nos leve a nos destruirmos a nós mesmos, tornando-nos ainda mais frágeis diante dos poderes que visam ampliar e aprofundar nossa própria precariedade.

\section{REFERÊNCIAS}

BRASIL. Conselho Nacional de Combate à Discriminação. Brasil sem homofobia. Programa de combate à violência e à discriminação contra GLTB e promoção da cidadania homossexual. Brasília: Ministério da Saúde, 2004.

BRASIL. Secretaria Especial dos Direitos Humanos. Anais da Conferência Nacional de gays, lésbicas, bissexuais, travestis e transexuais - GLBT. Direitos Humanos e Políticas Públicas. O caminho para garantir a cidadania GLBT. Brasília, 2008.

BRASIL. Ministério da Educação. Documento Final - Conferência Nacional de Educação-CONAE. Brasília, 2010.

BRASIL. Lei n ${ }^{\circ} 13.005$, de 25 de junho de 2014. Aprova o Plano Nacional de Educação (PNE) e dá outras providências. Câmara dos Deputados, Edições Câmara, Brasília, 2014.

BRASIL. Projeto de Lei $n^{\circ}$ 867, de 2015. Inclui, entre as diretrizes e bases da educação nacional, o "Programa Escola sem Partido”. Brasília, Câmara Federal, 2015. Disponível em: <https://goo.gl/EWfaVK>. Acesso em: 24 maio 2017. 
BOURCIER, M. H. L'homosexus normativus entre mariage unidimensionel et droits sexuels. Movements, 1, n. 49, p. 08-15, 2007.

BUTLER, J. Gender Trouble. Feminism and the subversion of identity. New York: Routledge, 1990.

CÉSAR, M. R. de A. Gênero, sexualidade e educação: notas para uma "epistemologia". Educar em Revista, n. 35, p. 37-51, 2009.

CÉSAR, M. R. de A. As novas práticas de governo na escola: corpo e sexualidade entre o centro e a margem. In: CASTELO BRANCO, G.; VEIGA-NETO, A. (Orgs.). Foucault filosofia e política. Belo Horizonte: Autêntica, 2011.

CÉSAR, M. R. de A.; DUARTE, A. M.; SIERRA, J. C. A estética da existência e as artes de viver: Michel Foucault e a crítica da noção de sujeito nos movimentos sociais feministas, LGBT e na educação. In: CLARETO, S. M.; FERRARI, A. Foucault, Deleuze \& Educação. Juiz de Fora: Editora UFJF, 2013.

CÉSAR, M. R. de A.; CUNHA, J. M. Transsexuality and School Education in Brazil. In: RUSSEL, S. T.; HORN, S. S. (Orgs.). Sexual Orientation, Gender Identity and Schooling. The Nexus Research, Practice and Policy. New York: Oxford University Press, 2016. p. 115-125.

CÉSAR, M. R. de A.; SANTOS, D. B. C. dos. (Des)politizando gênero e diversidade sexual nas Conferências Nacionais de Educação. In: SILVA, P. V. B; REIS, L. R.; TRIGO, R. A. E. (Orgs.). Educação e Diversidade: justiça social, inclusão e direitos humanos. Livro 2: CONAE Paraná: reflexões e provocações. Curitiba: Appris, 2015. p. 1-15.

CONFERÊNCIA EPISCOPAL PERUANA. La ideologia de género. Lima, Peru, 1998. Disponível em: <https://goo.gl/8vKYPc>. Acesso em: 24 maio 2017.

DAL'LGNA, M. C. Família S/A: um estudo sobre a parceria família-escola. Tese (Doutorado em Educação) - Programa de Pós-Graduação em Informática na Educação, Universidade Federal do Rio Grande do Sul. Porto Alegre, 2011.

FOUCAULT, M. História da sexualidade. A vontade de saber. Vol. I. Rio de Janeiro: Graal, 1984.

FOUCAULT, M. Segurança, território, população. São Paulo: Martins Fontes, 2008.

FOUCAULT, M. Qu'est-ce que la critique? Suivi de La culture de soi. Paris: Vrin, 2016.

ONU. Declaração e Plataforma de Ação da IV Conferência Mundial sobre a Mulher. Pequim, 1995. Disponível em: <https://goo.gl/DBqPvA>. Acesso em: 22 maio 2017.

PRECIADO, P. Quem defende a criança queer? 2013. Disponível em: <https://goo.gl/ hIib4E>. Acesso em: 22 maio 2017.

RICH, A. Compulsory heterosexuality and lesbian existence. ABELOVE, H.; BARALE, M. A; HALPERIN, D. M. (Ed.). The lesbian and gay studies reader. New York: Routledge, 1993. p. 227-254. 
RUBIN, G. Thinking sex. Notes for a radical theory of the politics of sexuality. In: ABELOVE, H.; BARALE, M. A.; HALPERIN, D. M. (Ed.). The lesbian and gay studies reader. New York: Routledge, 1993. p. 03-44.

SANTOS, D. B. C. Cartografias da transexualidade: a experiência escolar e outras tramas. 2010. Dissertação (Mestrado em Educação) - Programa de Pós-Graduação em Educação, Universidade Federal do Paraná. Curitiba, 2010.

SIERRA, J. C. Marcos da vida viável, marcas da vida vivivel: o governamento da diversidade sexual e o desafio de uma ética/estética pós-identitária para teorização político-educacional LGBT. 2013. Tese (Doutorado em Educação) - Programa de Pós-Graduação em Educação, Universidade Federal do Paraná. Curitiba, 2013.

Texto recebido em 21 de agosto de 2017. Texto aprovado em 09 setembro de 2017. 
